\title{
Study of Construction Techniques of Highways and Bridges on Soft Soil Foundation
}

\author{
Hainan Zheng* \\ Yunda Highway Project Department of Shenyang, Shenyang, Liaoning 110000, China
}

\begin{abstract}
S The quality of highways and bridges' foundation construction influences the overall quality of the projects directly. The soft soil layer shall be investigated in advance during construction in order to analyse and identify the specific reinforcement and processing approaches. The cost, processed effects and safety issues shall be considered prior to reinforcement. Different reinforcement approaches can be used in order to save the cost and ensure the quality of soft soil foundation reinforcement. This paper discusses the preparation of soft soil foundation construction and the technology involved in the construction of highways and bridges on soft soil foundation. It is expected that the study could provide some references to professionals.
\end{abstract}

\author{
KEYWORDS \\ Highway pavement \\ Soft soil foundation \\ Construction technique
}

\section{Introduction}

China's economy keeps developing and the highways and bridges construction also develop prosperously. The construction technique keeps improving, especially the achievements done in soft soil foundation construction. Soft soil foundation is the foundation that failed to meet the required bearing capacity of the construction on it; or it met the requirements during construction but due to internal or external reasons, failed to keep the stability and caused large or irregular subsidence and damages to buildings later.

There are two problems existed in soft soil foundation: Firstly, the intensity and stability of foundation. When the foundation's shear strength could not bear the external loads of pavement and embankment, the soft soil foundation would be damaged partially or completely leading to a instability, collapse or damages to highways and bridges. Secondly, the foundation sinks or shape changes. If the soft soil foundation sinks or changes shapes due to external loads, the highways would not be available to be used.

Copyright $\odot 2015$ Hainan Zheng

doi: $10.18686 /$ utc.v2i1.10

Received: October 3, 2015; Accepted: October 28, 2015; Published online: December 1, 2015

This is an open-access article distributed under the terms of the Creative Commons Attribution Unported License (http://creativecommons.org/ licenses/by-nc/4.0/), which permits unrestricted use, distribution, and reproduction in any medium, provided the original work is properly cited.

${ }^{*}$ Corresponding author: Yunda Highway Project Department of Shenyang, Shenyang, Liaoning 110000, China. E-mail: zhenghainan123@ sina.com
The characteristics of soft soil layer is that its void ration is large (up to 1.0-1.9), its moisture content is high (typically, it is $34 \%-72 \%)$, the saturation is above $95 \%$, the plastic limit is $13-30$ and the liquid limit is $35 \%-60 \%$. The goal of soft soil foundation process is to improve the bearing capacity and stability based on its characteristics [1].

\section{Preparation of Highway and Bridge Soft Soil Foun- dation Construction}

The preparation work is necessary to be done prior to highways and bridges constructions to ensure the geological conditions were confirmed and it is also convenient to do processes to soft soil foundation.

\subsection{Construction Marks}

Total station was used to confirm the king-pile before construction starts. Then, level gauge was used to measure the height and confirm the foot line of embankment. Edge line was placed according to soft soil foundation designing plan at every highway segment. Finally, lime was used to mark the line of the construction.

\subsection{Foundation Excavation}

Half range excavation was done at the construction section. First, excavation was carried out horizontally along the two sides of edge line of the construction section according to the designing plan. A trapezoid pit was excavated. The soil was poured at the two sides of the foundation. During excavation process, the water leakage was observed. If the water leakage volume is low, the soil's texture until was analysed until it reached the silt layer. The 
gravelly soil was backfilled. The height of backfilled ground shall be $30 \mathrm{~cm}$ higher than the horizon. If the water leakage volume is large, the foundation needs to be excavated into a transverse slope along the highway and the slope rate was $3 \%$ so that the ponding could be discharged along the edge line. At the same time, the throwing stones was adopted to packing sedimentation approach [2].

\subsection{Check the Bearing Capacity of the Foundation}

Penetrometer was used to test the foundation's bearing capacity when the soil's textures fulfilled the foundation soil's requirements. The parts that fail to meet the requirements in plan and of standards was fixed. Upon self-test and spot check, if they are qualified, the placement was performed in layers.

\section{Highways and Bridges Soft Soil Foundation Con- struction}

There are different soil textures and landforms in the construction of highways and bridges' foundations. The technologies and approaches to handle soft soil foundations shall be chosen based on actual conditions.

\subsection{Reinforcement of General Soft Soil Foundation}

There are three common approaches to handle general soft soil foundation reinforcement. They are throwing stones to packing sedimentation, cement injection pie and excavation and backfilling gravels. Throwing stones to packing sedimentation approach is to throw rubbles at the bottom of the foundation to push the sludge out of the bottom in order to increase the intensity of the foundation. It needs to drain the surface water, if necessary, it could use cofferdam to discharge the water. It needs to pay attention to intercepting ditch and drainage ditch to avoid ponding. This approach is typically used in soft soil or mire whose thickness is $3-4 \mathrm{~m}$ and the thickness is not large, the surface does not contain hard shell, the rubbles could sink to the bottom. Cement injection pile approach is to mix powders with original soil along with a certain amount of curing agent. Through physicochemical function, it would become mixed columns with certain intensity so that they would increase the intensity of the embankment. Typically, the curing agent would be cement. The preferred cement is 32.5 normal silicate cement. Excavation and backfill with rubbles approach is typically used in the soft soil foundation whose depth is not very large. After checked by dynamic sounding, excavate the soft soil at that section and backfill with gravels. During this process, the excavation shall be done by segments and backfill those segments one by one. The backfilled gravels' intensity shall no less than $15 \mathrm{MPa}$; the thickness of layer shall be no higher than 30 $\mathrm{cm}$; the maximum grain size of stones shall not be more than $2 / 3$ of the layer's thickness. The backfilled gravels shall be grinded by $320 \mathrm{kN}$ road roller according to the regulations. The backfilled gravels shall be tightly filled without loosening.

\subsection{Connecting Pieces Treatment Method 3.2.1 Bridges typically uses pile foundations}

They could ensure the safety and stability and the subsidence volume is very little. Soft soil foundation would have problems in irregular subsidence at the connecting parts between bridge and the embankment. This could be called as 'Height Difference' or 'Hump'. To avoid such issue, it needs to eliminate the negative frictional resistance of the pile foundation and to solve the inconsistent loads between highway and bridge. The commonly used approaches are preloading approach and balanced loads on embankment approach. The preloading approach is always used along with lime pile and vertical drainage well approaches. The preloading approach is to use the total loads that equivalent with the loads of the embankments to process the bridge's foundation. The loads were removed when the foundation is stable and then start to building of bridge abutment was started. This approach could eliminate the negative friction resistance of file foundation and irregular subsidence effectively. It is applicable to all kinds of bridge abutment as well as barricade. Balanced loads approach is used after the pre-loading approach. After the pre-loading approach was done, the column typed bridge abutment was used to dill on embankment and install piles. This could prevent the bridge abutment from longitudinal displacement and eliminate the negative frictional resistance of pile foundation as well as prevent irregular subsidence. Nevertheless, it is only applicable to column typed bridge abutment. The above mentioned approaches are frequently used to handle the soft soil foundation at the connection piece of highway and bridges. There are other approaches adopted at the same time to facilitate shortening the preloading time and improving the performance, e.g. sand compaction approach, bagged sand well approach, plastic drainage plate approach, sand bed approach, prevention of over load approach and etc. The advantages of pre-loading and balanced load approaches are that they are easy to operation with sound performance and low cost and low input of resources; the disadvantages are the pre-loading time is relatively long and during the pre-loading period, the construction cannot be proceeded [3].

\subsubsection{Soft Soil Foundation Treatment at the Connect- ing area of Channel, Culvert and Embankment}

The connection of channels, culverts and embankment. Normally, it would build channels and culverts first, and then the embankments on the two sides. Channels and culverts do not need pile foundation as they are relatively small, they would easily have irregular subsidence, slit up or ponding issues and eventually unable to function. Based on those reasons, it is recommended to use backwards slot, bearing piles, pre-reserved camber and enlarged cross section approaches. Backwards slot approach is actually 
pre-loading approach. It is to build the embankments first and use the same loads of the embankments on soft soil foundations under channels and culvert to make the soft soil sink. Construction can be started when the soft soil is stable. This approach is always used along with sand pile, sand bed, over load prevention and drain board techniques to accelerate the sinking of soft soil, shortening the preloading time and improving performance. It could avoid the problem of 'Hump' and control cost but it requires time to do pre-loading that will prolong the construction period. It has to set up temporary paths and pipelines in channels and culverts. The bearing pile approach is rarely used unless the construction time is tight and it is impossible to use pre-loading approach as well as the foundation subsidence exceeds the allowed range. The pre-reserved camber approach and enlarges cross section approach cannot eliminate the irregular subsidence but they could make the channels and culverts available to use when there is subsidence [4].

\section{Conclusion}

China has large areas with diversified geographical conditions. There would be all kind of problems encountered during the construction of highways and bridges. The ra- tional construction approaches shall be determined based on actual conditions to tackle soft soil issues encountered during construction. It is a must to handle the soft soil foundation issues properly prior to other issues to ensure that the soft soil foundation construction could proceed smoothly. This has significance contribution to the completion of the construction and safety is guaranteed during constructions in the future. The highways and bridges constructions on soft soil foundation in China is matured but it still needs to be improved and innovated to increase its safety and stability.

\section{References}

1. Zhu, M., \& Fan, J. H. (2009). Brief Discussion of Soft Soil Foundation Handling Approaches and Construction Techniques. West Exploration Engineering, 21(1), 26-28.

2. Chen, T. R. (2012). Discussion of Municipal Highways Construction Techniques. Private Science and Technique, 12, 222.

3. Tian, L. C. (2010). Analysis of Soft Soil Foundation of Highways and Bridges Construction. China High-Tech Corporation, 16, 141-143.

4. Wang, J. L. (2003). Handling Methods of Soft Soil Foundation of Highways. Science Intelligence Development and Economy, 6, 78-82. 